\title{
LA ATRACCIÓN DEL VINO EN LOS VIAJEROS EUROPEOS DE LOS SIGLOS XVIII Y XIX
}

\author{
Julio FERNÁNDEZ PORTELA \\ Departamento de Geografía. Universidad de Valladolid \\ Virginia ISLA GARCÍA \\ Dpto. de Literatura Española y Teoría de la Literatura Comparada. Universi- \\ dad de Valladolid
}

Recibido: $29 / 05 / 2012$

Devuelto: 28/06/2012

Aceptado: 21/08/2012

RESUMEN: La literatura y el vino son dos conceptos que han estado unidos desde la época clásica presentando una simbiosis que ha dado lugar a una relación muy estrecha entre ambos. Uno de los ejemplos menos estudiados de esta relación se encuentra en los libros de viaje de los siglos XVIII y XIX en los que se degusta y se reflexiona acerca del mundo del vino español.

En este sentido, el objetivo del artículo es recordar cómo se explicaba la impronta de la actividad vitivinícola y de la cultura del vino en el territorio nacional, con especial interés en la Cuenca del Duero y en Andalucía Occidental según los intereses particulares de viajeros ingleses y franceses y las características propias del libro de viajes (la inserción de esta realidad en sus itinerarios, la necesidad de congraciarse al público lector, haciendo referencia al universo cultural común y a las expectativas asociadas a este género de entretenimiento e información, etc.). Finalmente, sus descripciones en la literatura de viajes sobre el entramado de la industria del vino (la recolección, su elaboración, el almacenamiento, su consumo por diferentes clases sociales o su comercialización con otros países) se contrastarán con los testimonios españoles en otros géneros de la literatura de ficción desde el siglo XVIII hasta comienzos del siglo $X X$.

PALABRAS CLAVE: libros de viaje, vino, España, viajeros ingleses, viajeros franceses.

\section{THE ATTRACTION OF WINE ON THE $18^{T H}$ AND $19^{T H}$ CENTURY EUROPEAN TRAVELLERS}

ABSTRACT: Literature and wine are two concepts which have been together from classic times presenting a symbiosis which has given place to a very narrow relationship between them. One of the least studied examples of this relationship is found in the travel books from the $18^{\text {th }}$ and $19^{\text {th }}$ centuries where the Spanish wine world is both tasted and considered.

In this sense, the aim of the article is to remember how the stamp of the wine activity and the world of wine in the national territory, with special interest in the Duero basin and in Western Andalusia, is shown according to the particular interest of English and French travellers and the characteristics of the travel book (the insertion of this subject in their itineraries, the need to ingratiate himself to the reading public, making reference to common cultural uni- 
verse and the expectations associated with this genre of entertainment and information, etc.). Finally, theirs descriptions about the framework of the wine industry (its harvest, production, storage, and consumption by different social classes, commercialization in other countries such as England and France) will be checked with Spanish attestations in other literary fiction from the $18^{\text {th }}$ century to the beginnings of $20^{\text {th }}$ century.

KEY WORDS: travel books, wine, Spain, English travellers, French travellers.

\section{INTRODUCCIÓN: LA IMPORTANCIA DEL VINO EN LA LI- TERATURA OCCIDENTAL. CREATIVIDAD Y CULTURA}

Ya el Pseudo-Aristóteles en su Problema XXX explicaba la exaltación común del consumo del vino y los comportamientos artísticos como resultados ambos del exceso ocasional tanto de vino como de bilis negra, propiciadores en los dos casos del entusiasmo, la locura o la melancolía, estado de ánimo asociado a la creatividad. Este hecho explicaría, quizá, el por qué la relación entre creatividad y ebriedad, o lo que es lo mismo, el vino y sus efectos, aparece en la literatura universal como metáfora y propiciador habitual de la comunión del creador con las musas y lo sagrado. Así, el interés por este motivo ha dado lugar a interesantes estudios comparatistas como el realizado por Miguel Ángel Muro Munilla, El cáliz de las letras: Historia del vino en la literatura (2006) en el que encontramos testimonios desde los libros mesopotámicos hasta la actualidad, haciendo especial hincapié en la literatura hispana. En estos ejemplos vemos cómo el vino, independientemente de las funciones ya indicadas, se suele presentar como parte de un entorno favorable a su consumo, tales como cenas o comidas solitarias o ceremoniales, en lugares públicos (tabernas, fondas) o privados (el hogar) y entre compañías afines por el contexto social, la amistad, el deseo sexual y el amor.

Independientemente de los tópicos literarios, en el caso español el vino forma parte de una realidad histórica y social que caracteriza no sólo sus paisajes y su industria, sino que participa de una cultura particular presente tanto en la vida cotidiana como en la imagen que se exporta del país. De este modo, además de en la lírica, el tema del vino va a estar presente en otros géneros más propios de la ficción y de la representación del mundo, como el costumbrismo o la novela, así como en otros más reflexivos, como el ensayo, o partícipes de la rigurosidad científico-histórica como el libro de viajes. El desarrollo de estos últimos, en los que no se prescinde de la anécdota costumbrista o del ensayo, con un fin práctico, turístico y utilitario, será especialmente acusado a finales del siglo XVII hasta principios del XX, de forma paralela al sucesivo interés ilustrado, romántico, positivista y regeneracionista. En ellos veremos cómo, según la procedencia de cada autor y los intereses individuales y nacionales, la descripción de la cultura del vino en España 
se dibuja bajo intereses más o menos pintorescos y en gran parte comerciales. De este modo, la imagen de una España rural y apasionada se verá justificada en el paisaje, producción y efectos del vino, una representación simplista con la que no siempre los escritores españoles se mostrarán de acuerdo.

\section{ORIGEN Y EVOLUCIÓN DE LA VITICULTURA EN EL TE- RRITORIO ESPAÑOL: LA IMPRONTA SOCIO-ECONÓMI- CA DEL VINO.}

El origen de la viticultura en España es muy incierto. A pesar de los diferentes estudios que se han llevado a cabo para determinar el momento en el que se comenzó a desarrollar esta actividad, no se han establecido todavía fechas concretas. Algunos autores como Hidalgo (2003), establecen el comienzo de la viticultura en la Península Ibérica en el tercer milenio a. C. Los vestigios que se han encontrado en diferentes yacimientos arqueológicos en lugares muy distantes entre sí como en el sector de Jerez, Cádiz y el Puerto de Santa María (LóPez AMADOR y RuIZ GIL, 2007), en Padilla del Duero en la provincia de Valladolid (SANZ, 2009) o las pepitas de uva que han aparecido en las excavaciones de Cauca, actual Coca en la provincia de Segovia (SANZ, 2009), confirman el interés de los antiguos pobladores por la cultura del vino.

No obstante, se considera que fueron los romanos los que generalizaron el consumo del vino entre la población en los siglos III y II a.C. Desde entonces y hasta el siglo $\mathrm{V}$ d. C. se produjo una expansión muy significativa del cultivo del viñedo en la cuenca del Duero, en el Valle del Ebro y Valle del Guadalquivir, principalmente. Las posteriores invasiones de los pueblos germánicos arrasaron gran parte de lo que encontraban a su paso, incluidos los viñedos, que habían configurado, hasta entonces, un paisaje peculiar en los diferentes sectores del país. El último de estos pueblos que permaneció en la península fue el visigodo, desplazado por los musulmanes en el 711.

El avance de las tropas islámicas obligó a los habitantes de las tierras de la Cuenca del Duero a abandonar sus hogares y refugiarse en las ciudades de mayor tamaño, si bien muchos de ellos huyeron al Norte de la península. Diferentes autores se refieren a las llanuras de Castilla y León como una especie de Tierra de Nadie (HUETZ DE LEMPS, 2005) o una zona intermedia entre el reino astur y Al-Ándalus (VALDEÓN, 2006).

La derrota de los musulmanes ante los cristianos en la batalla de Covadonga en el 728 constituyó el origen de la reconquista. Desde esta fecha los cristianos comenzaron a cosechar diferentes victorias y fueron recuperando los 
territorios arrebatados y repoblándolos a medida que avanzaban hacia el sur peninsular.

Mientras tanto, en los Valles del Guadalquivir, del Tajo y del Ebro, los judíos jugaron un papel muy representativo en el cultivo y la elaboración de vino en ciudades como Calahorra, Logroño, Zaragoza, Toledo o Sevilla, además de otras grandes de mayor tamaño y sus entornos, situadas en el Mediterráneo como Barcelona o Valencia. Con el fin de poder abastecerse y comprobar el correcto proceso de elaboración del vino, o Kasher, realizaban ellos mismos todo el proceso de vinificación (PIQUERAS HABA, 2004).

Sin duda alguna, el papel más significativo en la repoblación lo tuvieron las órdenes monásticas a través de la reconstrucción y la creación de nuevas iglesias y monasterios. Los viñedos asociados a la Iglesia constituyeron el cultivo repoblador por excelencia. El largo tiempo transcurrido desde su plantación hasta la primera cosecha propició el establecimiento y consolidación de pequeños asentamientos de población cuya subsistencia dependía directa o indirectamente de la producción del vino.

A partir de este momento se fueron configurando unas determinadas comarcas vitivinícolas como la Tierra de Medina y Cigales en la provincia de Valladolid, la Ribera del Duero vallisoletana con Peñafiel y la burgalesa con Roa y Aranda de Duero, el área de la Mancha y Valdepeñas, los vinos andaluces de Jerez y Málaga, o Cariñena en Aragón. El vino que se elaboraba en estas áreas era muy variado al producir blanco, clarete y tinto, gozando de gran fama entre los estratos sociales más altos del país.

Desde el siglo XVIII y comienzos y mediados del siglo XIX, se asiste a la alternancia de fases de expansión del viñedo español, consecuencia del incremento del consumo del vino, con otros periodos de fuerte retroceso ocasionados por grandes plagas y epidemias como el mildéu, el oídio y sobre todo por la filoxera. A causa de esta última enfermedad se produjo el arranque de un número masivo de cepas entre finales del siglo XIX y comienzos del XX reduciendo casi el $100 \%$ de la superficie de vides en algunas provincias como Málaga, Barcelona y Gerona, y en otras como Valladolid y Zamora hasta un 50\% (SOLANO, 1990). Esta enfermedad ocasionó grandes desastres económicos en la economía rural de toda España, pero en especial en aquellas regiones eminentemente agrarias como Castilla y León, Cataluña y Andalucía, cuyo pilar fundamental era en muchos casos el viñedo, que no logró recuperarse hasta casi el último tercio del siglo XX. Los factores que contribuyeron a la reestructuración vitivinícola actual fueron la adaptación y creación de nuevas bodegas, la proliferación de las Denominaciones de Ori- 
gen, y la diversificación de la actividad productiva tradicional con nuevas funciones como el enoturismo (FERNÁNDEZ PORTELA, 2011).

Los vinos fueron adquiriendo una notoriedad entre los siglos XVIII-XIX que no solo era reconocida en España sino también en toda Europa y América. En general, la pertenencia de los viajeros a los estratos sociales más elevados de Francia e Inglaterra explicará su interés por los vinos de calidad de determinadas áreas geográficas españolas. El crecimiento de una poderosa clase media, en especial en la Francia del Segundo Imperio, hará extensiva a esta nueva clase social el consumo de estos vinos. De este modo, el vino se convertirá en un producto fácilmente accesible también para los intelectuales no pertenecientes, necesariamente, a la alta burguesía y aristocracia.

En los libros de nuestros viajeros quedarán plasmados sus aventuras, sus itinerarios, las descripciones de las ciudades, sus monumentos, obras de arte, etc. entre las que se incluirán algunas descripciones de los paisajes, de las bodegas y de la calidad de los vinos, con la intención última de satisfacer la curiosidad de un lector conocedor también de estos vinos. Así, el viajero confirmará, desprestigiará o alabará, según el caso, el caldo español, contribuyendo a publicitar en su país un vino que ya se conocía de antemano.

\section{LOS LIBROS DE VIAJES EN LA EDAD MODERNA: UNA MIRADA MULTIDISCIPLINAR A OTRAS REALIDADES.}

Tal y como dijimos anteriormente, la relación entre la literatura y el vino no se reduce sólo a su constante presencia como motivo temático, con mayor o menor simbolismo, en la poesía, teatro o ficción, sino que también se encuentra en las relaciones de los viajeros europeos por nuestro país desde la Edad Moderna. En ellas, las descripciones geográficas en torno al paisaje (viñedos, bodegas) se contextualizan con la narración de costumbres supuestamente típicas del «carácter español». Así, el viajero hará por presenciar los rituales cotidianos alrededor del vino, en tabernas o dependientes de la gastronomía, porque verá en ellos la mejor ocasión para propiciar una animada tertulia que le confirmará, generalmente, sus ideas previas acerca de los participantes. De este modo, además de destacar el papel ceremonial del vino, el viajero transforma la anécdota en un episodio literario con distintos fines, amenizados a menudo con la reflexión acerca del desarrollo económico del país, amén de señalar la merecida pausa en su itinerario.

Así, la pausa para saborear el caldo ayuda a estructurar el libro de viajes, formando parte de las etapas del citado itinerario (espacio) y su desarrollo cronológico (el tiempo) sin olvidar, como hemos dicho, su lugar en los acontecimientos más destacados. El descubrimiento, comparación y contraste con 
las costumbres del lugar de origen del viajero y destino principal de sus narraciones, hacen que, inevitablemente, la mirada extraña hacia el otro, llena de prejuicios y expectativas previas, se vea especialmente agudizada en el caso del viaje por España. Al fin y al cabo, el carácter periférico de nuestro país respecto al resto de Europa y su particular desarrollo histórico, la presencia árabe, su carácter imperial y universal tras el descubrimiento de América y su posterior declive y decadencia, desfavorecida además por la leyenda negra, había potenciado la imagen de un país tan ruinoso que no merecía la pena visitar. Este motivo fue la causa principal por la que se excluyó a España del Grand Tour ilustrado, itinerario europeo que todo joven de alta esfera social debía realizar para completar su educación. Este Tour permitía así al joven del XVIII cumplir con los preceptos educativos de Montaigne, Bacon o Rousseau, ya que se entendía que la ampliación de su formación intelectual le permitiría ser mejor ciudadano universal y contribuir al progreso de su propio país, idea que tendrá especial arraigo, como veremos, entre los británicos.

Sin embargo, en esta misma concepción del hombre comenzó a tomar fuerza la idea de que, para alcanzar la formación total era también necesario el cultivo de la propia sensibilidad, de tal manera que lo que en principio eran narraciones objetivas de viajes se fueron transformando en personales relaciones de las impresiones resultantes del contacto directo con la vida cotidiana y las costumbres. En esta búsqueda de lo emotivo y original, característica del romántico, España se convirtió en el destino por excelencia. De este modo, la ruina pasó progresivamente de ser objeto de desprecio a principal motivo de atracción para el aventurero, que, sin embargo, como veremos, no dejó nunca de mostrar su recelo por el atraso político y social del español, idea que perdurará hasta bien entrado el siglo XX. Por otra parte, no olvidemos que el sufrimiento en primera persona del atraso hispano constituía una excelente publicidad para el escritor, ahora aventurero, que se habría sacrificado para satisfacer la curiosidad del pasivo lector, al tiempo que buscaba halagarlo con la exaltación de las bondades de su propio país.

Tanto por cercanía geográfica como por interés económico y cultural, la mayoría de los viajeros que recorrieron España desde los siglos XVI hasta el XIX, fueron franceses e ingleses aunque también hubo italianos (PORRAS, 2010), portugueses (GARCÍA-ROMERAL, 2001), rusos (FERNÁNDEZ, 1985) así como de otras nacionalidades (PLASENCIA, 1995). También había latinoamericanos quienes contemplaban el país movidos por los contradictorios sentimientos que las colonias o excolonias desarrollan habitualmente hacia su metrópoli (ZULUETA, 2002). 
Las motivaciones de los viajeros dependen en gran parte de las relaciones de su país con el de destino. De este modo, los franceses y los ingleses destacan por su interés intelectual y comercial. Así, los dos se enfrentaron sobre el suelo español en la Guerra de la Independencia (1808-1814) siendo ambos países de asilo de los exiliados españoles al finalizar esta. A partir de este momento el francés se sintió fascinado por el exotismo español, alimentado antes y después por la literatura, mientras que el inglés afianzó sus industrias y empresas en el sur español. La progresiva pacificación española así como las mejoras en las ciudades y comunicaciones facilitaron el flujo constante de viajeros a lo largo del siglo.

En general, los viajeros europeos del XVIII pertenecían, por razones obvias, a las clases altas (nobles y clero) y a menudo eran o iban a ser miembros influyentes en los gobiernos de sus países. Según avance el movimiento romántico y sobre todo, tras las guerras napoleónicas, el viajero provendrá de una clase media más o menos acomodada y sus motivaciones serán más personales a medida que el viaje pase a ser un entretenimiento más entre las opciones de ocio. Con la mejora de las condiciones del viaje comenzarán a aparecer más viajeras entre ellos, acompañando a sus maridos o bien solas, aunque sus observaciones serán sobre todo de tipo costumbrista en relación a las tertulias, museos, etc. (ECHEVARRÍA, 1995). Destacaremos, en todo caso, la aparición del viajero como escritor profesional (especialmente entre los franceses) aunque debemos suponer junto a estos el mantenimiento de un flujo constante de comerciantes, empresarios o banqueros, tan amantes de las aventuras de los primeros como reacios a experimentar las previsibles incomodidades de estas.

\section{LA PERSPECTIVA DE LOS VIAJEROS INGLESES ANTE EL COMERCIO, LA INDUSTRIA Y EL PAISAJE VITIVINÍCOLA ESPAÑOL.}

Los relatos de viajes por parte de viajeros ingleses constituyen un testimonio esclarecedor de las costumbres, las formas de vida y las tradiciones de todo el territorio español. Pese a la tradicional movilidad del viajero británico en búsqueda y mantenimiento de contactos comerciales por todo el mundo, los viajes a nuestro país no comenzaron a generalizarse hasta la segunda mitad del siglo XVIII ya que antes de esta fecha y desde la decadencia de los Austrias la Península Ibérica apenas suscitaba interés cultural y desde luego tampoco económico. España había sido apartada del Grand Tour que realizaban aquellos ingleses que poseían mayores recursos económicos al considerar el país como un espacio poco cosmopolita, así como por las dificultades encontradas en la comunicación y el transporte, impedimentos que representaban una tarea ardua y complicada para los sofisticados viajeros ingleses 
acostumbrados a un sistema de comunicaciones más accesible y mejor desarrollado acorde con su elevado nivel económico Según las expectativas de estos viajeros, España poco podía aportar a este viaje, cuyo fin era eminentemente educativo y tenía como principal destino Francia e Italia, aunque en ocasiones se recorrían también algunos países del centro de Europa como Alemania, Holanda y Suiza.

Para la realización de este viaje se requería un buen conocimiento previo del territorio en materias como geografía, historia, literatura, legislación, etc; eran necesarias cartas de presentación y de crédito; pasaportes; contar con un buen criado que estuviese preparado en idiomas, que supiese escribir, con nociones básicas de medicina y capaz de solucionar cualquier tipo de problema que se plantease (FREIXA, 1993). Sólo cuando decayó el interés por estos países antes citados se decidió visitar otros nuevos entre los que se incluían España y Portugal, siendo la decadencia española uno de los temas más recurrentes en este tipo de libros.

La mayor parte de los viajeros ingleses eran hombres y estaban formados en universidades de prestigio de Inglaterra como Cambridge. Solían ser militares, comerciantes, escritores, políticos y en ocasiones clérigos. Como se dijo anteriormente, el objetivo principal de sus viajes era la ampliación de su formación personal, por lo que la mayor parte de estos presentaban un carácter educativo, aunque algunos viajeros pretendieran también cambiar la imagen errónea que tenía la población inglesa de España. La duración de estos viajes solía ser generalmente de un año y el itinerario era diverso, dependiendo de las diferentes entradas a la Península a través de Francia, La Coruña, Portugal o Gibraltar. ${ }^{1}$

Fueron muchos los ingleses que recorrieron España describiendo los aspectos más característicos del país destacando las reseñas de las ciudades y de sus principales monumentos: palacios, iglesias, castillos, universidades, etc. Comparaban la situación de la agricultura, la industria y el comercio con la propia Inglaterra, las técnicas de cultivo, la sociedad de la época, sus costumbres, etc. Pero, sin duda alguna, uno de los temas más recurrentes y que estaba presente en la obra de prácticamente todos los viajeros que llegaron a España fue el sector vitivinícola. El mundo del vino constituyó un tema muy recurrente en las diversas descripciones llevadas a cabo por los distintos autores. Las observaciones que realizaban sobre el mundo del vino iban desde

\footnotetext{
${ }^{1}$ Los viajeros recorrían amplias zonas del territorio peninsular haciendo especial hincapié en la costa, los principales puertos marítimos, las ciudades más importantes, el País Vasco, la capital madrileña, otras residencias de la corte, las ciudades universitarias... frente a otras regiones como Castilla La Mancha o Aragón que constituían lugares de paso (GUERRERO, 1990)
} 
las plantaciones, su elaboración, las bodegas y las técnicas de cultivo hasta el precio, su consumo en las posadas y la localización en el territorio, ensalzando la figura de los vinos, ya que era un producto que los ingleses apreciaban y debían exportarlo de lugares como Jerez y Málaga, convirtiendo este mercado en un asunto de Estado.

Los viajeros más destacados que recorrieron el territorio español y dejaron constancia de la impronta de la actividad vitivinícola fueron Richard Ford, Thomas Roscoe, Joseph Townsend, Arthur Young, Richard Croker, Richard Twiss o James Howel, entre otros. Entre todos ellos hay que destacar la presencia de dos mujeres, aspecto que no solía ser muy habitual, Mrs William Pitt Byrne y Lady Fanshawe.

\section{IV.1. El interés de los viajeros ingleses por el negocio del vino en Espa- na.}

Uno de los intelectuales ingleses más representativos fue Joseph Townsend (1739-1816). Estudió medicina en la Universidad de Cambridge, se ordenó como sacerdote y se le consideró uno de los viajeros británicos que más se involucró en el país. Era hijo de un acaudalado comerciante, lo que le permitió realizar el Grand Tour y posteriormente viajar a España para escribir una de las obras más completas titulada A journey through Spain in the years 1786 and 1787; with particular attention to the agriculture, manufactures, commerce, population, taxes and revenue of that country. Esta obra fue traducida al francés, al alemán y al español. Su narración se enmarcaba dentro de los viajes llamados filosófico/ilustrados, ya que su objetivo era dar a conocer bastantes aspectos de la sociedad española. Durante su estancia en España se interesó por una amplia gama de temas, siendo la vegetación, los suelos, la economía, pero sobre todo el comercio sus principales pasiones. En su obra las referencias al cultivo de la vid y a la elaboración de vino son muy numerosas ensalzando la calidad de estos caldos, especialmente los de los territorios de Castilla la Vieja y Andalucía. ${ }^{2}$ En el caso de Castilla destaca la existencia de buen vino y un paisaje vitivinícola hermoso que se combina con los campos de cereales tan característicos de esta región. En su viaje de Madrid a Asturias atravesó de Sur a Norte toda la región y descubrió una zona vitivinícola con superficies muy amplias de viñedo que producían vinos blancos de calidad muy apreciados en la capital vallisoletana y en su entorno. De ellos comenta: "El vino blanco de toda esta zona es excelente, y

\footnotetext{
${ }^{2}$ Aunque los vinos de Castilla, La Mancha y Andalucía son los que merecen más comentarios por parte de este autor, hay que mencionar otras comarcas vitivinícolas españoles a las que Townsend hace referencia por sus vinos, como es el caso del producido en los alrededores de Zaragoza, al que tilda de excelente, sobre todo en las temporadas secas (PlASENCIA, 1995)
} 
aunque no resulta tan dulce y aromático como el de Fuencarral, cerca de Madrid, la delicadeza de su sabor es semejante" (TownsEND, 1998: 143).

Tras su estancia en Asturias regresa a Madrid atravesando de nuevo Castilla la Vieja, donde vuelve a narrar la impronta del cultivo, en este caso en la provincia de Salamanca: "Tras atravesar este bosque empezamos a descender por un territorio de hermosos cultivos y rico en trigo y vino, que nos condujo a Alba, ciudad que dista de Salamanca cuatro leguas cortas" (TOWNSEND, 1998: 301). La importancia de los viñedos salmantinos tenía su origen en la sólida actividad religiosa de la ciudad, pero sobre todo en la Universidad, gran foco de consumo de vino.

Tras atravesar Madrid y narrar la actividad económica, política, social y cultural de la ciudad, se encuentra en la provincia de Toledo con un municipio llamado Camuñas muy rico en vino de excelente calidad. Pero fue sin duda el vino de Valdepeñas el que obtuvo grandes elogios por parte de este autor. Este vino era muy conocido en Madrid, ya que prácticamente toda su producción se consumía en la capital. Como dijimos, la actividad comercial era una de las pasiones de Townsend, razón por la cual insistía en que el vino de La Mancha tendría una gran demanda de mercado en Inglaterra si se abriese un canal navegable entre este sector vitivinícola y Sevilla que permitiese transportar este caldo hasta el puerto y después enviarlo a Inglaterra.

Finalmente, llegó a Andalucía, a la que se podía llamar la bodega de Inglaterra, principal destino de los vinos transportados desde los puertos del suroeste andaluz. De los vinos andaluces comentaba que los mejores eran el jerez y el pajarete, aunque su precio se incrementaba de forma considerable durante su traslado a este país:

"El primero se vende a cuarenta y ocho libras el tonel, y el otro, a cincuenta y seis. Cuando son exportados a Inglaterra pagan un derecho de aduana de dieciséis guineas, y un impuesto de consumo de once libras y dieciocho chelines la tonelada, que equivale a cuatro toneles grandes o dos barricas. En Londres cuesta dos libras y dieciséis chelines más" (TOWNSEND, 1998: 301).

En líneas generales, Joseph Townsend alaba en todo momento la calidad de los vinos españoles y los considera un cultivo esencial tanto para España como para Inglaterra. Estima que son de buena calidad, que abundan en el territorio y ensalza su buen precio, lamentándose únicamente de que en ocasiones sean destinados a la destilación.

Otro de los grandes autores que describe estos paisajes y la industria española es Richard Ford (1796-1858). Abogado y periodista, sin duda alguna es 
uno de los viajeros que más conoció y más escribió sobre España. Narró los aspectos culturales, sociales y naturales de todo el país, haciendo especial incidencia en algunos sectores como el vino, del que era un gran conocedor, aunque su atención se dedicó sobre todo al espectáculo taurino. Vivió en España entre 1830 y 1833 y gracias a esta larga estancia pudo escribir algunas de sus obras más representativas como Handbook for travellers in Spain and readers at home publicado en 1844, Ghaterings from Spain en 1846 y The Spanish bull fights en 1852. Fue un apasionado del país, lo que no le impedía plasmar en sus obras la realidad objetiva de todo aquello que narraba (PLASENCIA, 1995).

Sus conocimientos en aspectos vínicos le permitieron hacer valoraciones de la producción de este caldo por todo el territorio peninsular. En su opinión, los viticultores españoles primaban la cantidad sobre la calidad (aspecto que también se encuentra en la obra de Townsend). Manifiesta que en algunos sectores, a pesar de los pocos cuidados que recibían los viñedos, se obtenían excelentes caldos gracias a los condicionantes físicos como la latitud, el clima y el suelo que les permitían competir con los vinos franceses.

También en este caso vuelven a ser los vinos de Castilla y León y los andaluces los que mayores comentarios merecen por parte del autor.

De Castilla y León describe la expansión de este cultivo por los campos de muchos sectores como los de Toro, Cigales, Aranda de Duero, Medina del Campo, El Bierzo o León, entre otros. En sus salidas a esta región elogia la calidad de estos caldos y describe las bodegas localizadas en los sótanos de las casas y en las laderas de los páramos.

El autor pudo comprobar que el comercio del vino constituía un factor clave en el desarrollo económico de las principales villas y su entorno como Valladolid, León o Medina del Campo. Esta última, debido a su localización estratégica a unas 14 leguas de ciudades como Palencia, Zamora, Segovia, Ávila y Salamanca, y a 8 de Valladolid (Ford, 2008c), era ya un consolidado centro comercial de gran envergadura al que llegaban comerciantes, sobre todo del Norte peninsular, en busca de los productos de estas zonas, entre ellos el excelente vino que elaboraban. ${ }^{3}$ Algo similar ocurría en los alrededo-

\footnotetext{
${ }^{3}$ La comarca de Medina, con municipios como Rueda, La Seca, Serrada o Medina del Campo, era uno de los sectores de mayor elaboración de vino y de excelente calidad que experimentaron un importante auge con la instauración de la corte en la capital vallisoletana entre 1601-1606 repercutiendo de forma positiva en la economía de la población: «Rueda, con dos mil quinientos habitantes, tienen también una buena iglesia parroquial y una bella calle larga. Es una de las mejores ciudades de la comarca, ya que la gran cantidad de buen vino que se hace aquí es fuente de beneficios para los habitantes. Los viñedos están en terreno pedrego-
} 
res del municipio burgalés de Aranda de Duero, encrucijada de caminos del norte e importante centro religioso, aristocrático y social (FORD, 2008b) ${ }^{4}$.

Aunque existen un sin fin de referencias sobre esta actividad en otros territorios en Castilla y León conviene reparar en sus impresiones acerca del área andaluza, como se señaló, distribuidora oficial de los vinos para el mercado inglés. Al igual que Townsend, Ford también destaca la importancia que poseían los puertos como Cádiz, Sanlúcar, Jerez y el Puerto de Santa María en el transporte del vino para su comercialización en las Islas Británicas (FORD, 2008a). Posteriormente, este importante comercio daría lugar a inversiones de capital muy grandes por parte de empresarios ingleses en la mejora de las bodegas existentes con soleras de calidad, en la creación de otras nuevas y la plantación incluso de viñedos propios que produjesen el tan ansiado caldo. Un ejemplo sería la incorporación como socio de Robert Blake Byass en las bodegas de González y Dubosc en 1855.

Los vinos de este sector se elaboraban con el objetivo de satisfacer los gustos de los consumidores ingleses. Vinos como el Jerez habían sustituido a mediados del siglo XIX la exportación de los fuertes vinos portugueses, en parte debido a un cambio en los hábitos alimentarios, pasando el vino a formar parte del aperitivo o la comida de la mesa inglesa y, por lo tanto, haciendo preferible el consumo de caldos más ligeros (PAN-MANTOJO, 1994). Por otro lado, esta moda por el Jerez supondría a la larga su progresiva manipulación. Así señala Ford (2008a) que, frente al marrón espeso del Jerez tradicional los nuevos vinos crudos eran más pálidos con el objetivo de halagar los gustos de algunos ingleses. De este modo, el jerez pálido debía de ser obtenido a toda costa por lo que el color se suavizaba químicamente a expensas del aroma del vino.

Dejando aparte los citados ejemplos del Jerez (en manos inglesas) o el valdepeñas, a Ford también le llamará la atención la falta de cuidado y el atraso de las técnicas en el estrujado de la uva y en el almacenamiento del vino, situación en realidad común a todo el interior peninsular que contrasta con los alegres esfuerzos de los campesinos, para quienes la vendimia forma parte de su propia existencia. Así describe Ford:

\footnotetext{
so y accidentado; el vino se conserva en grandes barriles de roble, y se considera buen remedio contra la gota. A esta ciudad vienen los maragatos y los comerciantes de vinos del norte a hacer sus compras, trayendo hierro y productos coloniales para el trueque» (FORD, 2008c).

${ }^{4}$ Actual D.O. Ribera del Duero. Este sector ha sido considerado siempre como uno de los centros productores de vino más representativos de la región junto con su vertiente vallisoletana con centro neurálgico en Peñafiel.
} 
"Muchas veces hemos atravesado pueblos fragantes con el aroma del vino e inundados con el zumo de uva, hasta que el mismo barro estaba enrojecido, iqué bulliciosa escena! Burros cargados con canastos llenos del maduro fruto; muchachas encorvadas bajo el peso de las cargadas banastas; hombres con las piernas y los brazos rojizos, alegres y joviales como sátiros, rellenando apresuradamente la tosca y sucia cuba, en donde se meten las uvas indistintamente, las blancas y las podridas, sin ningún esmero, sin hacer la menor selección. La suciedad y el abandono con que se hacen todas las demás operaciones ocurren parejas con esta primera. Se prensa la uva con los pies desnudos o con vigas del sistema más primitivo, y en los dos casos, todas las operaciones de clasificación se dejan a la fermentación natural, porque hay una divinidad que dispone de nuestros destinos y se deja que las cosas salgan como buenamente puedan" (PLASENCIA, 1995:35)

Finalmente, el tercer autor analizado es Richard Twiss (1747-1821). Este viajero, hijo de un rico comerciante, aunque realizó el Grand Tour como todo joven inglés acomodado, después de este decidió visitar también España y Portugal. La atracción por estos países se debía precisamente al escaso interés que suscitaban entre el resto de los viajeros que los consideraban más atrasados que otros como Francia, Italia o Suzia. Twiss esperaba encontrar cosas totalmente nuevas y diferentes al resto de países que había visitado en el campo de las artes y la literatura (GUERRERO, 1990). Su obra más representativa fue Travels trhough Portugal and Spain in 1772 and 1773, que sirvió de referencia para autores franceses y alemanes contemporáneos.

El recorrido que realizó Twiss fue similar al de Townsend. Entró por el país luso, donde visitó Lisboa, Coimbra y Oporto entre otras ciudades, haciendo su entrada en España por el entorno del Duero en la provincia de Salamanca, de donde destacó sus campos muy ricos en cereales, quejigos y encinas. En su obra destaca la impronta que tenía el viñedo en Castilla del que comenzó a dar testimonio en los alrededores de los núcleos de Toro y Tordesillas. Estas poblaciones abastecían de vino a su entorno más inmediato pero sobre todo a las capitales que concentraban gran parte de la población civil y religiosa.

Tras su estancia en Madrid, en la primavera de 1773 se dirigió hacia el Levante, encontrando a su paso viñedos y cereales en los alrededores de Aranjuez. El vino que aquí se producía, debido a la cercanía con la capital española, se consumía en Madrid. A su llegada a la costa alicantina, pudo comprobar la importancia que tenía el comercio del vino, de la sal y la sosa desde este puerto, aunque no se alcanzaban las cifras que se manejaban desde 
Jerez, Cádiz o Sevilla. Desde Alicante se trasladó a Murcia y posteriormente a Andalucía, visitando Granada, Córdoba, Málaga, Sevilla y Cádiz. Respecto a los productos españoles, Twiss (1999) destaca la exportación del vino por ser la más beneficiosa para la economía nacional debido a su amplio consumo en las Antillas, Uruguay y Argentina. Posteriormente, este vino se iría sustituyendo, de forma paulatina, por el vino producido en sus propios países.

Como se ha podido comprobar en el testimonio de estos tres autores, el vino español constituía un elemento clave tanto en la vida social de los ingleses como en su economía por los grandes intereses de sus empresarios en el sector vitivinícola andaluz. Por este motivo, como dijimos, los relatos de viaje británicos se centran en las descripciones del paisaje vitivinícola, del proceso de elaboración del vino y de su conservación en los diferentes tipos de bodegas, destacando siempre su comercialización en Inglaterra, donde la preocupación por la calidad de los caldos dotaba a estas informaciones críticas de un valor inestimable.

\section{EN BUSCA DE LO PINTORESCO EN EL PAÍS VECINO: LOS VIAJEROS FRANCESES.}

Como se ha señalado, la Guerra de la Independencia marcó un antes y un después en el interés francés por España. La disputa entre afrancesados y patriotas, el exilio con el absolutismo fernandino, la presencia de los Cien mil hijos de San Luis y, sobre todo, su descubrimiento para el Romanticismo, como reducto de lo exótico, lo oriental y lo tradicional en una Europa marcada por el progreso, contribuyó al afianzamiento de la imagen de España como un país al margen de la caracterización y evolución común del continente

En general, los viajeros mostraron muy poco interés por explorar el norte peninsular (con la excepción de Lantier en el País Vasco) realizando un viaje casi directo a Andalucía bien por Madrid y la Mancha o bien por el Levante español. En todo caso, llevados en parte por su afán por toparse con una España pobre plagada de bandoleros y exguerrilleros, se horrorizan por la mala calidad de los caminos, fondas y tabernas, aunque la realidad debió de mejorar a medida que avanzaba el siglo.

Por otro lado, aun cuando los viajeros todavía no presupongan la existencia real de unos tópicos literarios, tal como harán los escritores e historiadores decimonónicos, sus precursores del XVII y del XVIII llamarán también la atención sobre el mal estado del país vecino. Pertenecientes estos a las clases ilustradas, sacerdotes (Muret, Labot, Vayrac), enviados en embajadas 
(Saint Simon, Silhouette) a veces incluso amigos de reformistas como Jovellanos (Bourgoing), se mostrarán críticos con la situación del país. Por otro lado, se sabe que ciertos vinos eran ya conocidos en esta época gracias a la difusión de obras literarias como El Quijote, quien llega a confundir en sus sueños los odres de vino con gigantes (I, 35). No obstante, aunque en general los comentarios de estos viajeros franceses fueron elogiosos, siempre establecían la comparación del vino española con el producto de la patria: «Beben vino en La Mancha, que es muy bueno, de un sabor aproximado al Borgoña, pero de una delicadeza inferior; es el vino que beben los príncipes, el rey bebe vino de Borgoña» .

\section{V.1. Las impresiones del viajero decimonónico en torno al vino como parte de la industria y de la esencia española.}

Iniciamos nuestra descripción con las impresiones de Louis Joseph Alexandre Laborde (1773-1842). Hijo de padre vasco de familia acomodada, sufrió el exilio en Viena durante el Régimen del Terror. Allí se formó en el ejército mientras viajaba por gran parte de Europa adquiriendo una serie de conocimientos que pronto le hicieron ganar la estima de Napoleón, acompañándole antes y durante la guerra en las campañas de España y Austria. Hombre también de inquietudes artísticas, consiguió el apoyo español y francés para la elaboración de su Voyage Pittoresque et Historique, resultado de sus viajes en 1806. Sin embargo, tras la Guerra de la Independencia tuvo que autofinanciar su publicación definitiva en 1820 con la inserción de grabados de numerosos artistas. Previa a esta edición, había publicado en 1808 una guía para el ejército napoleónico titulada Itineraire descriptif de l'Espagne, aunque su gran proyecto sería el Voyage, compendio del patrimonio artístico español previo a la Guerra y a sus expolios, que ejercería «una gran influencia en la fijación de los tópicos y de los estereotipos culturales de los viajeros románticos que, durante el siglo XIX, visitaron la Península Ibérica» (QUílEZ y CASANOVAS, 2006). De hecho, su itinerario, cuya ordenación seguiría una base histórica, sería imitado por la mayoría de los viajeros posteriores. Consistiría en dos rutas, una por la costa del Levante con incursiones a Zaragoza, pueblos catalanes y valencianos, hasta llegar a Andalucía y otra más tradicional desde Roncesvalles pasando por Pamplona, Burgos, Valladolid, Segovia, Madrid y Extremadura, culminando en Cádiz.

Siguiendo la tendencia arriba mencionada, cuya imitación la convertirá en habitual, Laborde discrimina los vinos castellanos a favor de los franceses,

\footnotetext{
${ }^{5}$ Silhuette, Voyage de France, d'Espagne, de Portugal e d'Italie (1729-1730). Citado sin página por Plasencia (1995: 103).
} 
cuando cuenta como el vino de Cigales, durante el reinado de Carlos III, aumentó de calidad gracias a las experimentaciones con el método francés, que, sin embargo, no tuvieron continuidad ${ }^{6}$. Crítica similar será la de Louis Lande casi un siglo después en Basques et navarrais. Souvenirs d'un voyage dans le nord de l'Espagne. Al igual que hizo Ford, Lande se quejará del descuido en la "exposición de las bodegas, la dimensión de las cubas o el grado de fermentación" cuya mayor aberración será su almacenamiento para la venta en los odres de piel de caprino, salvo casos excepcionales como los del señor de Riscal, quien antes de la filoxera y ayudado por la maquinaria moderna cultivaría la uva autóctona junto a las mejores viñas del Medoc con excelentes resultados ${ }^{7}$.

Muy distinto será el caso de los vinos andaluces, tildados siempre de variados y abundantes. Entre ellos Laborde destaca los granadinos porque tienen "perfume y un aroma muy agradables" y los malagueños, de los que llega a señalar tres cosechas. En la tercera los entendidos distinguen dos tipos de vinos "el lágrima y el guindas. El primero es la madre de los mejores pagos; el último es el vino de Málaga ordinario, en el que se echan las yemas todavía tiernas de los cerezos, cuyos frutos se llaman en español guindas"

El amor por España de Charles Davillier (1823-1883), aristócrata francés, conocido coleccionista e hispanista, le llevó a rodearse de importantes escritores, pintores y anticuarios españoles, como Martín Rico, Raimundo y Ricardo Madrazo o Fortuny en su casa-museo de Pigalle. Probablemente, fue en una de estas tertulias en las que organizó junto al famoso dibujante Gustave Doré, ilustrador de la Divina Comedia, El Quijote, etc., uno de sus viajes más importantes a España, el realizado en 1862 y descrito en su Voyage en Espagne, cuyas crónicas fueron financiadas por la revista Le Tour du monde.

Aunque siguieron básicamente el itinerario de Laborde (costa levantina, Andalucía, y regreso por ambas Castillas y el País Vasco), la visión realista del barón, opuesta en parte a la búsqueda de lo exótico de los románticos, le permitió elaborar una relación rigurosa y detallada de la vida española (diversiones, oficios, etc.) dejando a Doré la plasmación gráfica, un tanto personal, tanto de los monumentos y ruinas, como de los tipos, campesinos, toreros, etc. que situaba en ellos. Se detuvieron especialmente en los antiguos reinos sevillanos y granadinos, donde prestará especial atención a la cerámica del Al Ándalus así como a las mujeres trabajadoras de la Fábrica de Ta-

\footnotetext{
${ }^{6}$ Laborde citado sin referencia por PlasENCIA (1995: 92)

${ }^{7}$ Louis Lande, citado sin página por PlASENCIA (1995: 126 y 128)

${ }^{8}$ Laborde citado sin referencia por PLASENCIA (1995: 132, 138 y 140)
} 
bacos, representadas en compañía de bandoleros y gitanos tal y como se reproducía en la conocida Carmen de Merimée (1845) y se popularizará mucho más adelante en la famosa ópera de Bizet (1875).

Como parte de la cultura del país, Davillier observa el consumo y producción del vino tanto en el norte del país (País Vasco, La Rioja, a la que llama la Andalucía del Norte) como en el Sur. No obstante su rigurosidad, también en él son frecuentes las comparaciones del vino español con el francés, siendo siempre el último superior al primero, tanto por su calidad como por su producción. De este modo, el chacolí de las tierras vascas, equivalente a su piquette le parece "un brebaje áspero, agrio y poco sustancioso" (DAVILLIER, 1957: 930); las viñas de Valdepeñas, cuya calidad reconoce, dan la casualidad, sin embargo, de que «según se asegura, fueron antiguamente importadas de Borgoña» aunque en la actualidad deberían compararse con "algunos vinos del mediodía de Francia, por ejemplo, con el Chateauneuf-du-Pape o con otros viñedos de las costas o del Ródano" (DAVILLIER, 1957: 567); en otros casos, como los levantinos, recoge la opinión generalizada de que se mezclaban en los Pirineos con otros vinos y pasando por Burdeos, se vendían en el resto de Europa, lo cual, aunque no hace demasiado bien a la publicidad del Burdeos, convierte al vino español en un vino difícil de vender por sí mismo pero excelente para adulterar otros (DAVILLIER, 1957: 342-348). Esta circunstancia dificultaría, en general y salvo las excepciones mencionadas, la exportación del vino español como producto de calidad.

Llevado quizá por el chovinismo o, tal vez, demasiado pendiente de sus lectores, Davillier sólo parece prescindir en parte de sus comparaciones cuando habla de los vinos andaluces, especialmente del famoso y «nuevo» Jerez. Cita con detalle sus bodegas más conocidas, los viñedos, los talleres de tonelería, su fabricación minuciosa y conservación, prácticamente toda en manos de británicos como las que surgieron a finales del XVIII de los acuerdos entre Thomas Osborne Mann, James Duff y William Gordon. Al fin y al cabo, aún a mediados del siglo XIX y hasta la moda del Claret, el vino francés tenía la batalla perdida con el Jerez en la vecina Inglaterra.

En último lugar, tal y como hemos repetido en otras ocasiones, los viajeros franceses más famosos a lo largo del XIX fueron los escritores profesionales, quienes buscaban en España, y sobre todo en Andalucía, las aventuras exóticas que formaban parte de sus lecturas y de sus propios relatos. Así, la fascinación por España común a Víctor Hugo, Edgar Quinet, Próspero Merimée, Alejandro Dumas o Teófilo Gautier, entre otros, les hacía recorrer el país con la infantil esperanza de tropezarse en cada paso con aguerridos bandoleros y apasionadas gitanas, viéndose a menudo decepcionados, como fue el caso de Dumas. La realidad de una España de tabernas sucias y despachos de 
vino se hacía más llevadera con la degustación de sus caldos, como la manzanilla, mencionada por primera vez en francés en la citada Carmen de Merimée, uno de los escritores que más visitaría la exótica Andalucía en sus viajes entre 1830 y 1855, inmortalizándola en sus Lettres en Espagne.

De este modo, si bien a veces el gusto de la bota le amargaba a Gautier la experiencia de vinos como los alicantinos ${ }^{9}$ (eso si no eran timados por los fondistas como los de Valdepeñas, como cuenta Alejandro Dumas que le sucedió a él y a su tropa, en su impreciso De París a Cádiz (1992: 219), en general, los escritores daban buena cuenta de los caldos españoles, a los que acudían no siempre en busca de la inspiración poética. Sirva de ejemplo la exquisita borrachera de Gautier en las bodegas jerezanas que nada tiene que ver con otras peninsulares, como las que había encontrado en Dueñas, en Castilla la Vieja, las cuales «cavadas en la roca viva, reciben la ventilación por torrecillas de forma de turbante, que ofrecen un falso aspecto de minarete muy singular» (FigueroA y Melgar, 1997: 246) ${ }^{11}$. Por otro lado, en la descripción de las jerezanas se repiten gran parte de las características ya señaladas en otros autores:

"Jerez, como todas las pequeñas ciudades andaluzas, está blanqueada de cal de los pies a la cabeza, y no tiene nada notable arquitectónicamente salvo sus bodegas, o almacenes de vino, inmensas naves de elevadas cubiertas de tejas, con largos muros blancos exentos de ventanas. La persona a la que estábamos recomendados se encontraba ausente, pero la carta hizo su efecto, y nos condujeron inmediatamente a la bodega. Jamás se ofreció espectáculo más glorioso a los ojos de un borracho; paseamos entre hileras de toneles dispuestos sobre cuatro o cinco niveles de altura. Tuvimos que probar de todo, al menos de los principales tipos. Seguimos toda la gama desde el jerez de ochenta años, oscuro, espeso, con gusto a moscatel y la tintura extraña del vino verde de Béziers, hasta el jerez seco color de paja claro, con olor a piedra de chispa y próximo al sauternes. Entre estas dos notas extremas hay todo un registro de vinos intermedios, con tonos de oro, de topacio tostado, de cáscara de naranja, y una variedad extrema de gus-

\footnotetext{
${ }^{9}$ Gautier citado sin referencia por Plasencia (1995: 122). Suponemos que se refiere a Voyage en Espagne, 1840.

${ }^{11} \mathrm{Al}$ hablar de las bodegas de Dueñas, Gautier comenta la existencia de unas torres que se asemejan a un minarete. Estas torres son los denominados respiraderos que poseen la mayor parte de las bodegas de Castilla. La función de este elemento era ventilar la bodega en los periodos de elaboración del vino. A través de los huecos que poseían los respiraderos podían salir los gases, conocidos como tufo, que emanaban del proceso de fermentación y que resultaban mortales para las personas.
} 
tos. Sólo que todos están mezclados más o menos con aguardiente, sobre todo los que se destinan a Inglaterra, donde sin él no les encontrarían suficientemente fuertes; pues, para agradar a los gaznates británicos, el vino debe estar disfrazado de ron"12

Podríamos decir, por lo tanto, que los viajeros franceses, escritores o no, por su curiosidad y búsqueda de lo pintoresco, se fijaron especialmente en la cultura del vino andaluza, aunque mencionaron otros como el famoso Valdepeñas.

Así, pese a su preocupación por el descuido español, en sus narraciones destacan las constantes comparaciones con las producciones francesas y se recuerda la subordinación en este sentido del vino español, de tal manera que vinos como los riojas, los catalanes o el brandy jerezano se concebían como variantes españolas de los medocs, champagnes y cognacs franceses (PANMANTOJO, 1994: 266). Es más, de alguna manera, parece que el viajero galo se complace en remarcar este prestigio vitivinícola como un ejemplo más de la superioridad francesa frente a la pintoresca e inferior cultura española.

\section{LA RÉPLICA DE LOS AUTORES ESPAÑOLES A LOS TESTI- MONIOS EXTRANJEROS.}

Una vez estudiados los testimonios de los viajeros europeos acerca de la producción y consumo de uno de los alimentos más identificativos con nuestra cultura como es el vino, consideramos necesario recoger, aunque sea brevemente, los testimonios de los escritores e intelectuales españoles, contemporáneos a los primeros, para comprobar hasta qué punto se ajustaron a la realidad del momento.

En general, los viajeros extranjeros esperaban encontrar en España el mismo vino, sino mejor, que el que consumían con tal denominación en sus países. Cuál sería su sorpresa al paladear en su lugar unos caldos demasiado fuertes, con fuerte olor a las pieles de cabrito, que como dijimos, le hacían perder calidad en su conservación.

Quizá su asombro habría ido menor si hubiesen sabido que, tradicionalmente, el vino exportado de alta gama era en realidad reservado para el consumo de las clases privilegiadas también en España (SIMPSON, 1997) y que, por tanto, se consideraba un producto de lujo incomparable a los caldos servidos en las tabernas y despachos de vinos, vino común procedente de las

\footnotetext{
${ }^{12}$ Gautier citado sin referencia por PlASENCIA (1995: 144).
} 
zonas cercanas, y que era el que, como hemos visto, solía ser el destinado para el consumo del pueblo y de los incautos viajeros.

La identificación del vino como producto nacional es un hecho que ya Jovellanos da por supuesto en su Informe en el Expediente de la Ley Agraria (1794). En él, reflexiona acerca del precio del vino según la oferta y la demanda y propone políticas liberales para su producción (3.IV). En todo caso, lo considera un producto de lujo para consumo de las familias ricas (3.VIII). En esta línea ilustrada de preocupación por el progreso del país, Antonio Ponz (Viaje de España, 1772) insistirá también en la mala distribución de los cultivos, entre ellos el vino, ya que apenas se presta atención a la optimización del suelo y se dedica a los vinos terrenos que podrían servir para producir otros alimentos básicos para la población.

Pese a la abundante producción de vino, el consumo de este, y en general de las bebidas alcohólicas, debía ser relativamente reducido en España, al menos en comparación a la desmedida afición británica por las bebidas alcohólicas, entre ellas nuestros vinos, tal y como hemos señalado al hablar de sus industrias y exportaciones en el sur de España. Ejemplo del entusiasmo inglés es la crónica de Fernández de Moratín en su viaje a Inglaterra (17921793), donde se sorprende por el uso y abuso de este tipo de bebidas en todas las celebraciones, desde las tabernas hasta la mismísima Corte. Evidentemente, consecuencias de este consumo desmedido (al menos para el ilustrado), son los brindis y las posteriores discusiones que se suceden de forma diaria (Anotaciones, caps. 7 y 9). Por otro lado, el mismo Moratín en su regreso al continente (1793-1796) y ante la visión de los viñas europeas, comienza a reflexionar acerca de la particularidades del vino español: "Cuantas viñas he visto desde Bonn a Lucerna, todas están como las de Burdeos, esto es, trepados los sarmientos en estacas, y las cepas a unas tres cuartas de distancia unas de otras; no sé si este método es preferible al que se sigue comúnmente en España, o si será relativo a la situación, al clima o a la calidad de la tierra" (Viaje a Italia, cap. 2).

Sin embargo, aunque maticemos los excesos españoles comparándolos con los ingleses no podemos olvidar que, en la misma época, el también cosmopolita José Cadalso recoge en sus Cartas Marruecas (1789) el excesivo consumo del vino en los cortijos por parte de un pueblo y de una juventud desocupada (Carta VII), así como la moda afrancesada entre las clases altas urbanas quienes alternan el minuet con champagne (Carta XXXV). Esta crítica, en consecuencia con la condición árabe y por tanto abstemia del viajero corresponsal de las Cartas, es necesariamente condenatoria, ya que singulariza en el vino los muchos males que alimentan el exceso de ociosidad espa- 
ñola, pecado que en el caso de los ingleses no impedía sino que celebraba la prosperidad nacional.

El costumbrismo romántico, por su parte, si bien se propone en cierto modo responder a las falacias de los viajeros anteriormente citados, se nutre de los mismos tópicos para aderezar de sabor local sus ficciones. Así, Larra en El Castellano Viejo (1832), confirma la calidad de los vinos españoles que no es extensiva a sus consumidores. De hecho, la desastrosa comida se adereza con vinos malos de taberna (LARRA, 2002: 11 y 20), tan malos quizá como el que probó Dumas, ya que no era costumbre en las casas mantener una pequeña bodega para el consumo propio (PLASENCIA, 1995: 41 y 42). Sólo era posible encontrarlos en las casas pudientes, tal y como se cita en la novela El poeta y el banquero (1842), símbolo de prosperidad y excusa para el desarrollo del episodio de la borrachera del criado negro (II, cap.21), episodio que podría remitir incluso al Celoso Extremeño de Cervantes (1613).

Por otro lado, el consumo del vino en la taberna, lugar de ocio y de reunión, aparece a menudo como excusa para el diálogo entre los tipos costumbristas, tal y como vemos en Las Escenas Andaluzas de Estébanez Calderón, aunque a veces es sustituido entre las clases populares por la manzanilla. En Los filósofos en el figón (1846) el narrador es testigo de la disputa entre dos compadres acerca de las virtudes que tiene el vino sobre la mujer, disputa que nos recuerda al medieval debate entre el Agua y el Vino. Se insiste aquí en la calidad del vino español, cuya fortaleza es alabada por los protagonistas, quienes discuten también acerca de la satisfacción que da su tranquilo y sosegado consumo: "remojarse en vino como esponja, cual tú dices, es cosa, amigo, de hombre y paladar poco delicado, y para ti, mal vinagre o buen Jerez todo será igual, y quiero morirme si puede hallarse mayor pecado en buen bebedor, pues contigo será en balde aquello del pan con ojos, el queso sin ojos y el vino que salte a los ojos" (ESTÉBANEZ, 1999).

La preocupación por la falta de políticas reguladoras acerca de la producción, productividad, oferta y demanda del vino que habíamos visto en los autores del XVIII será de nuevo motivo de reflexión y crítica por los intelectuales naturalistas y del 98, aunque en estos casos la reforma tendrá un matiz social, haciéndose eco por primera vez de las reivindicaciones de los campesinos.

En la transición entre la recreación costumbrista con tintes líricos y la crítica por el atraso de la industria viticultora española, se encuentran la escritora gallega Emilia Pardo Bazán y su descripción de la vendimia en El cisne de Vilamorta (1885). Bello paisaje, locus amoenus realista necesario para la trama de la novela, los viñedos vecinos a Vilamorta pertenecen a un antiguo 
aristócrata de ideas enciclopedistas, que si bien son tildadas de caducas, se ven como positivas en cuanto a la buena fe con la que introduce técnicas extranjeras en sus viñas:

"Hacía ensayos tratando de imitar con el vino común del Borde del Burdeos de pasto; de prestarle, con polvos de raíz de lirio, el bouquet, la fragancia de los caldos franceses. Pero le salía al paso la rutina, el fanatismo (...) Los demás cosecheros del país le acusaban de olvidar las sanas tradiciones; de adulterar y componer el vino (...) Él se contentaba con aplicar los métodos racionales, los descubrimientos científicos, los adelantos de la química moderna, proscribiendo el absurdo empleo de la pez en las corambres, pues si bien la gente del Borde alababa el dejo a pez en el vino, diciendo que la pez hacía beber otra vez, a los exportadores les repugnaba, con razón, aquel pegote."(Cap. IX)

Tendremos que esperar a las novelas de principios de siglo, La Voluntad de José MARTínEZ RUIZ (1902) y La Bodega del naturalista Vicente BLASCO IBÁÑEZ (1905) para encontrar referencias a la filoxera, cuyas consecuencias económicas y sociales, como ya adelantamos al inicio, fueron cruciales en el desarrollo rural del país.

Así, fue a partir de la invasión de los viñedos franceses por parte de este parásito cuando se comenzaron a establecer unos vínculos de unión muy fuertes entre los viticultores franceses y los españoles, sobre todos los del tercio Noreste de la Península en regiones como Cataluña, Aragón, Valencia, Navarra y La Rioja. En estas dos últimas, la conexión por ferrocarril con Irún, constituyó un elemento clave para trasladar el vino al país galo ${ }^{13}$. La pérdida de prácticamente todos los viñedos franceses les obligó a buscar vino en otros países, principalmente en España. Debido a la tosquedad del método de elaboración, al que ya hicimos referencia, los franceses decidieron introducir el método bordelés de envejecimiento y conservación para obtener caldos de mayor calidad, adaptados al gusto francés. De esta forma, la superficie de vid española experimentó un crecimiento sin precedentes en su historia con 500.000 nuevas hectáreas y una superficie total de 1,7 millones en 1889 (PIQUERAS HABA, 2005), conformado un paisaje agrario nunca visto hasta la fecha.

\footnotetext{
${ }^{13}$ Ya Pardo Bazán, concluye la novela citada señalando la importancia que la llegada del tren va a tener para la difusión del vino: «Se habló, en efecto, de cosas alegres y satisfactorias: el señorito de Romero había ofrecido poner en Vilamorta estación telegráfica; y también se decía mucho en los papeles que la importancia vitícola del Borde reclamaba un ramal de ferrocarril, y pronto vendrían los ingenieros a estudiarlo » (Cap. XXVII).
} 
Esta expansión llegó a su fin con la llegada del insecto a la península por tres focos bien distantes entre sí, Málaga, Gerona y Oporto. Este hecho, sumado a la competencia argelina, perjudicó fatalmente a este sector, por lo que el viñedo español que había vivido una coyuntura muy favorable durante el último cuarto del siglo XIX, decayó a partir de comienzos del siglo XX con el arranque masivo de vides que se realizó como consecuencia de la enfermedad en la vid.

La replantación que se llevó a cabo en este periodo nunca alcanzó la superficie que fue afectada por la filoxera. Las nuevas plantaciones de origen americano fueron el único remedio a esta industria que languidecía económica y socialmente en un medio rural con fuerte presencia de las vides. A pesar de esta reconstitución del viñedo nunca se alcanzó la superficie existente antes de la enfermedad.

De este modo, en las novelas señaladas, se hace hincapié a la transformación que conllevó esta enfermedad a nivel social e industrial. Si bien en $\mathrm{La}$ Voluntad, Azorín se exalta en un monólogo en el que desde su conciencia social critica la falta de previsión de la enfermedad y la mala gestión de los campos, inundados de cepas que ya no valen nada ${ }^{14}$, la novela de Blasco Ibáñez ofrece una amplia descripción de la vida de las bodegas de Jerez, propiedad de los Hermanos Dupont (nombre que enmascara a los Domecq, de origen francés), que por su carácter más industrial habían sabido reponerse, como vimos, con la introducción de la vid americana, «una innovación nunca vista en Jerez», gracias a la cual la bodega «volvería a sus tiempos gloriosos sin miedo a nuevas invasiones» (cap. 4).

Teniendo como telón de fondo las huelgas y revoluciones de los cantones anarquistas, propuestas populares a la desigualdad y la pobreza, las bodegas de la novela de Blasco Ibáñez se convierten en escenarios de auténticas bacanales, único momento de comunión entre el propietario y trabajador, en las

\footnotetext{
14 «Estos pobres labradores - decía yo- han sido ricos un momento y luego volvieron a unirse con la miseria. Duró el contento lo que duró el tratado con Francia, relativo a los vinos, o sea de 1882 a 1892 . Entonces, como los vinos alcanzaban grandes precios, los labradores dedicaron sus tierras a la vid. ¡No más olivos, ni cereales, ni almendros, no frutales! Una hectárea de cereales producía 200 pesetas; una hectárea de viñero, 1.000. ¡Y todo fueron viñas! (...) Luego el tratado con Francia acaba; llega la depreciación de los vinos; poco a poco la alegría se apaga; los ensanches de los pueblos se paralizan. ¡Se alza la formidable usura! (...) Hoy el labriego está ya muy cansado: la fe le contiene aún en la resignación. Dentro de algunos años -los que sean-, cuando la propaganda irreligiosa haya matado en él la fe, el labriego afilará su hoz y entrará en las ciudades. Y las ciudades, debilitadas por el alcoholismo, por la sífilis y por la ociosidad, sucumbirán ante la formidable irrupción de los nuevos bárbaros... » (Cap. VI, El pulpillo)
} 
que, sin embargo, el vino compromete la virtud de las jornaleras (cap.5) por lo que se aúna en torno al vino la emoción y el vicio. Al fin y al cabo, el vino, "veneno alcohólico", corrompe a los explotados campesinos (cap.5), pero al mismo tiempo estos sienten por él un orgullo instintivo como si se tratara de su hijo (cap.4). Por eso mismo el técnico se lamenta de que, por exigencias del mercado, apenas abastecido por culpa de la filoxera, sea obligado a imitar y adulterar el líquido para hacerlo pasar por Madera, Oporto u otros vinos, o tenga que reducir su producción por culpa de la reciente afición británica por otro tipo de bebidas como el whisky al tiempo que decrece la exigencia en el jerez, satisfaciéndose ahora la demanda con el de peor calidad (cap.1). Se habría pasado del ascenso y popularidad comercial a la adulteración (recordemos, ya manifiesta por Ford) y falsificaciones en territorio nacional y en el extranjero, dando como resultado el desprestigio y declive del jerez (PAN-MANTOJO, 1994: 78). Este hecho se vería agravado por la crisis post filoxera provocando finalmente un aumento del paro y de la pobreza en la zona, la emigración y las revueltas campesinas de las que hemos hablado más arriba.

Lo que ha cambiado, sin embargo, es la discriminación social entre los consumidores del vino. El jerez continúa embotellándose con el fin de ser exportado o bien consumido por las clases privilegiadas del país, ya que se consideran vinos de consumo real (aunque los franceses lo describieran sólo como vino de príncipes) mientras que el vino de peor calidad, envejecido apresuradamente, se destinaba a las tiendas de comestibles o a las tabernas, es decir, como hemos dicho, al consumo del pueblo o de los viajeros que no gozaran de las recomendaciones que exhibía Gautier (La Bodega, cap.1). Este hecho explica por qué cuando el propietario de La Bodega quiere ganarse a sus jornaleros, actúe de forma paternalista igualándolos con él mediante el consumo del jerez de oro y suave fuego: «le alegraba ver enloquecer al rebaño miserable con el vino de los ricos. Era un placer de patricio romano, embriagando a sus clientes y esclavos con bebida de emperadores» (cap.7). De nuevo vemos cómo el problema en torno a la comercialización del vino, señalado ya por los ilustrados, continúa siendo, entrado el siglo $\mathrm{XX}$, un problema de Estado y como tal, ignorado.

\section{CONCLUSIÓN.}

Como expusimos en la introducción, la relación entre la literatura y el vino puede ser estudiada desde distintos puntos de vista, según prestemos atención bien al aspecto creativo, bien a su recurrente presencia en la cultura social. En nuestro caso, consideramos necesario recordar y profundizar la presencia de los caldos en un género tan marginal como el de los libros de viajes en su época de mayor popularidad, los siglos XVIII y XIX. Así, vimos 
cómo la problemática social, económica e incluso paisajística del sector vitivinícola formaba parte tanto de la estructura como del contenido de estos libros, de tal manera que las informaciones que recogen en este sentido no sólo se reducían a datos descriptivos sino que se veían manipulados por los intereses de los autores y del público al que iban dirigidos, consumidores ambos grupos de los vinos españoles en sus países de origen.

Teniendo en cuenta este conocimiento previo, no es de extrañar que las críticas en torno al vino degustado en territorio peninsular tiendan a comparar este caldo con el conocido en su país. Más allá de las motivaciones particulares de cada viajero (aventureras y románticas en el caso de los franceses, formativas y comerciales en el de los británicos), constatamos una tendencia a destacar el atraso tecnológico de la industria del vino que contrasta con la admiración que causaba el paisaje vitivinícola o con la dificultad en reconocer como tales los respiraderos de las bodegas castellanas, cuyo vino se destinaba principalmente al autoconsumo frente a las grandes empresas del sur andaluz.

No erraríamos demasiado al afirmar que es el consumo foráneo de un vino de calidad, rara vez accesible incluso en territorio peninsular, lo que predispone a los viajeros extranjeros a realizar una serie de críticas que sólo en parte son reafirmadas por los autores españoles, quienes tienden a destacar su consumo en colectividad en tabernas o en acontecimientos sociales de un vino, por lo tanto, común y procedente en general de las localidades más cercanas. El contraste entre la degustación de este vino y el consumido por los viajeros, personajes pertenecientes a clases sociales pudientes, aristócratas o, mediado el siglo XIX, burgueses, tenía que ser, cuanto menos, sorprendente.

En todo caso, aun cuando no consideremos la recurrente comparativa entre el vino común y aquel de mayor calidad, vemos cómo los viajeros parten de una idea del vino español asociada a sus hábitos de consumo. Así, el británico presta atención al proceso de formación y exportación de un Jerez, dependiente hasta tal punto de sus gustos, que los cambios de estos llegarán a provocar la ruina de poblaciones enteras nacidas en torno a la moda de este producto en sus Islas. Por otros motivos, pero equivalentes en impacto, las subordinación del vino español al francés tampoco se pondrá en duda, lo que tendrá como consecuencia la ruina del campo español con la recuperación de las viñas francesas tras la filoxera y el resurgimiento de sus hegemonía en el comercio del vino europeo.

Podemos decir, por lo tanto, que esta nueva mirada a los testimonios acerca de los caldos españoles en los libros de viajes nos ha permitido contextua- 
lizar la realidad descrita en su relación con los intereses particulares de los países de origen y comprobar la importancia que tuvieron no sólo en la exportación de los vinos sino también en la imagen que se publicitaba de ellos, imagen divulgada de forma amena, aunque quizá demasiado interesada, en los escritos de nuestros viajeros.

\section{BIBLIOGRAFÍA.}

BLASCO IBÁÑEZ, V. (1999): La bodega. Madrid, Cátedra.

CADALSO, J. (1999): Cartas marruecas. Alicante, BVC.

CERvantes, M. de (1999): El ingenioso hidalgo Don Quijote de la Mancha. Alicante, BVC.

CERVANTES, M. de (2001): El celoso extremeño. Alicante, BVC

DAVILlieR, C. (1957): Viaje por España. Madrid, Castilla.

Dumas, A. (1992): De París a Cádiz. Madrid, Silex.

ECHEVARRíA, E. (1995): Andalucía y las viajeras francesas en el siglo XIX. Málaga, Universidad de Málaga.

ELÍAs, L.V. (2008), «Paisajes del viñedo: patrimonio y recurso», Pasos Revista de turismo y patrimonio cultural, $\mathrm{n}^{\circ}$. 6, 137-158.

ESTÉBANEZ, S. (1999): Escenas andaluzas. Alicante, BVC.

FERNÁNDEZ, J. (1985): Viajeros rusos por la España del siglo XIX. Madrid, El Museo Universal.

FERNÁNDEZ DE MoRATín, L. (1999): Anotaciones sueltas de Inglaterra. Alicante, BVC.

FERNÁNDEZ DE MORATín, L. (2000): Viaje a Italia. Alicante, BVC.

FERNÁNDEZ PORTELA, J. (2011), «La bodega tradicional como elemento patrimonial: el cambio a la actividad industrial en la Denominación de Origen de Cigales y Ribera del Duero» Conferencia Internacional de la Vid y el Vino, (Almendralejo 8-11 febrero de 2011).

FigueroA y MelgaR, A. de (1971): Viajes románticos por España. Madrid, Escuelas Profesionales Sagrado Corazón.

FLORES, X. (1967): Estructura socioeconómica de la agricultura española. Barcelona, Ediciones Península.

FORD, R. (2008a): Manual para viajeros por España y lectores en casa, Andalucía. Madrid. Ediciones Turner.

FORD, R. (2008b): Manual para viajeros por España y lectores en casa. Madrid y Castilla. Madrid, Ediciones Turner.

FORD, R. (2008c): Manual para viajeros por España y lectores en casa. Extremadura y León. Madrid, Ediciones Turner.

FREIXA, C. (1993): Los ingleses y el arte de viajar. Barcelona, Serbal.

GARCíA, J. (1999): Viajes de extranjeros por España y Portugal. Desde los tiempos más remotos hasta comienzos del siglo XX Tomo I. Salamanca, Consejería de Educación y Cultura de la Junta de Castilla y León.

GARCÍA-ROMERAL, C. (2001): Viajeros portugueses por España en el siglo XIX. Madrid, Miraguano. 
GARcía SANTAmaríA, P. (1993): «Los viñedos riojanos durante la segunda mitad del siglo XIX», Cuadernos de investigación geográfica, Tomo IX, 83-98.

GUERRERO, A.C. (1990): Viajeros británicos en la España del siglo XVIII. Madrid, Ediciones Aguilar.

Hidalgo, L. (1964): El viñedo. Madrid, Servicio de Estudios del Banco Urquijo. Comisión de estudios agrarios.

HidAlgo, J. (2003): Tratado de enología. Madrid, Mundi-Prensa.

Huetz DE LEMPS, A. (2005): Vinos y viñedos de Castilla y León. Valladolid, Consejería de Agricultura y Ganadería de la Junta de Castilla y León.

Jovellanos, M.G. (2010): Informe sobre la ley agraria. Alicante, BVC.

LARRA, M.J. (2002): El castellano viejo. Alicante, BVC.

LÓPEZ AMADOR, J.J.; RuIZ GIL, J.A. (2008): «Arqueología de la vid y el vino en el Puerto de Santa María». Revista de Historia de El Puerto, n³8, 11-36.

MARTíneZ, J. (1973): La Voluntad. Madrid, Castalia.

MATA, P. (1842): El poeta y el banquero. Barcelona, Constitucional.

Molleví Bortoló, G.; Serrano Giné, D. (2007): «El impacto de la filoxera en Andalucía según la diplomacia francesa». Cuadernos Geográficos, n40, 133 148.

MONTAÑÉs, E. (2001): Viñas, bodegas y mercados. El cambio técnico en la vitivinicultura española 1850-1936 .Zaragoza, Prensas Universitarias de Zaragoza.

MORILla CRITZ, J. (1989): «Cambios en la viticultura de Andalucía Oriental durante la crisis de finales del siglo XIX. Estudios sobre los datos de los Informes Consulares Británicos». Revista de Historia Económica, nº1, 157-193.

Muro, M.A. (2006): El cáliz de las letras: historia del vino en la literatura. Logroño, Fundación de la Dinastía Vivancos.

NAREDO, J.M. (2004), La evolución de la agricultura en España (1940-2000), Universidad de Granada, Granada.

Pan Montojo, J. (1994): La bodega del mundo: la vid y el vino en España. Madrid, Alianza Editorial.

PAN MonTojo, J. (2005): «La viticultura en el siglo XX: una perspectiva desde el Mediterráneo». Mediterráneo e historia económica, $\mathrm{n}^{\circ}$ 7, 312-328.

PARDO, E. (2002): El cisne de Vilamorta. Alicante, BVC.

PiQueras HabA, J. (2004): «Los judíos y el vino en España siglos XI-XV. Una geografía histórica». Cuadernos de Geografía, $\mathrm{n}^{\mathrm{o}}$ 75, 17-41.

PIQUERAS HABA, J. (2005): «La filoxera en España y su difusión espacial: 18781926». Cuadernos de Geografía, $\mathrm{n}^{\circ}$ 77, 101-136.

Plasencia, P. (1995): Los vinos de España vistos por los viajeros europeos. Madrid, Ministerio de Agricultura, Pesca y Alimentación.

PonZ, A. (1972): Viaje de España. Madrid, Atlas.

PORRAS, S. (2010): Viajeros italianos en España: Cádiz en los libros de viajes del siglo XIX. Cádiz, Universidad de Cádiz.

[PSEUDO]Aristóteles (2007): El hombre de genio y la melancolía: problema XXX. Barcelona, Acantilado.

Quílez, F. y CASANOVAS, J. (2006): El viaje a España de Alexandre Laborde. Exposición MNAC. En línea: http://www.mnac.es/doc/lan_003/Laborde_cast.pdf. 
SANZ, M.J. (2000): «El barón Davillier, viajero y coleccionista». Laboratorio de Arte, $\mathrm{n}^{\circ} 13,223-240$.

SANZ, F. (1981): El viñedo español. Madrid, Ministerio de Agricultura, Pesca y Alimentación.

SANZ, C. (2009): El vino y el banquete en la Europa prerromano. Valladolid, Centro de Estudios Vacceos «Federico Wattenberg » de la Universidad de Valladolid.

SiMPSON, J. (1997): La agricultura española (1765-1965) la larga siesta. Madrid, Alianza Editorial.

SolAno, M.T. (1991): La crisis del viñedo. La filoxera en España. Tesis doctoral. Madrid. Editorial de la Universidad Complutense de Madrid.

TESTE, Luis (1959): Viaje por España. Valencia, Castalia.

TOWNSEND, J. (1988): Viaje por España en la época de Carlos III (1786-1797). Madrid, Ediciones Turner.

TwISs, R. (1999): Viaje por España en 1773. Madrid, Alianza.

UNwIN, T. (2001): El vino y la viña. Geografía histórica de la viticultura y el comercio del vino. Barcelona, Tusquets Editores.

VALDEÓN, J. (2006): La Reconquista. El concepto de España: unidad y diversidad. Madrid, Editorial Espasa.

Zulueta, J. M. (2002): Viajeros hispanoamericanos por la España del fin de siglo (1890/1904). Cádiz, Universidad de Cádiz. 